Review Article

\title{
Trends towards Effective Analysis of Fluorinated Compounds Using Inductively Coupled Plasma Mass Spectrometry (ICP-MS)
}

\author{
Ruth Lorivi Moirana (D), Thomas Kivevele, Josephine Mkunda, Kelvin Mtei, \\ and Revocatus Machunda
}

The Nelson Mandela African Institution of Science and Technology (NM-AIST),
School of Material Energy Water and Environmental Sciences, P.O. Box 447, Arusha, Tanzania

Correspondence should be addressed to Ruth Lorivi Moirana; ruth.moirana@nm-aist.ac.tz

Received 16 July 2020; Revised 15 January 2021; Accepted 22 January 2021; Published 3 February 2021

Academic Editor: Hana Sklenarova

\begin{abstract}
Copyright (C) 2021 Ruth Lorivi Moirana et al. This is an open access article distributed under the Creative Commons Attribution License, which permits unrestricted use, distribution, and reproduction in any medium, provided the original work is properly cited.

Increased demand for monitoring and identification of novel and unknown fluorinated compounds (FCs) has demonstrated the need of sensitive fluorine-specific detectors for unknown FCs in both biological and environmental matrices. Inductively coupled plasma mass spectrometry (ICP-MS) is a promising technique for analysis of FCs and has been rated as the most powerful tool in analytical chemistry. However, direct determination of fluorine using this technique is challenged by high ionization potential of fluorine together with spectral and nonspectral interferences which affect the quality of results. To enhance the quality of results, several studies have reported modifications of a conventional ICP-MS analysis procedure on sample preparation, introduction, analysis, and instrument optimization. Therefore, the focus of this study is to discuss different ICP-MS optimizations and future trends towards the effective analysis of FCs using ICP-MS.
\end{abstract}

\section{Introduction}

Human activities have led to the establishment of a wide variety of fluorinated precursors. Interaction of these precursors with the environment creates novel fluorinated compounds (FCs). Yeung et al. (2016) reported that novel fluorinated chemical structures make up to $60-90 \%$ of total FCs in biological and environmental samples $[1,2]$. Yamashita et al. (2004) further revealed that organisms found at the bottom of the food chain have at least higher concentrations of organofluorines which can neither be detected by high-performance liquid chromatographyelectrospray ionization-mass spectrometry (HPLC-ESI-MS) nor ionizable by atmospheric pressure chemical ionization (APCI) [3]. The ESI-MS technique exhibits a challenge with a selective nontargeted analytical system as data cannot be extracted magnificently by the mathematical algorithm to identify a given number of $\mathrm{F}$ atoms.

Determination and quantification of biologically and environmentally essential ions have significantly caught the attention of researchers in the field of analytical chemistry. This has made fluorine (F), which has certain unique properties such as the smallest radius, hard Lewis basic nature, and high charge density, one of the most extensively studied anion [4]. Additionally, F determination is crucial to contemporary environmental analysis due to its wide natural occurrence and anthropogenic synthesis of its precursors [5].

Chromatographic [6], spectrometric [7], electroanalytical [8], titrimetric [9], and potentiometric [10] techniques have successfully been used for the determination and quantification of FCs in matrices [11]. Other methods such as radiochemical, enzymic, polarographic, and gravimetric have also been utilized, although not prevalently [12]. The chromatographic method [6] comprises ion chromatography (IC), liquid chromatography (LC) (also referred to as high-performance liquid chromatography (HPLC)), and gas chromatography (GC). Whereas spectrometric techniques involve inductively coupled plasma mass-spectrometry (ICP-MS), inductively coupled plasma-optical emission 
spectrometry (ICP-OES) [11], and X-ray fluorescence spectroscopy (XRF), the electroanalytical method utilizes electrospray ionization (ESI) [13].

Recently, ICP-MS has been utilized successfully for nontargeted fluorine determination and quantification in biological and pharmaceutical samples with limited studies on environmental samples [14]. Determination of FCs with ICP-MS techniques is hampered by the high ionization energy of $\mathrm{F}$ together with spectral and nonspectral interferences. These challenges have been overcome for some time now through the modification of conventional analysis procedures of sample preparation, introduction, analysis, and instrument optimization [15]. Therefore, this study discusses trends towards achieving effective nontargeted analysis of FCs using ICP-MS.

\section{The Occurrence of Fluorinated Compounds (FCs)}

Fluorine was first found in human sera in 1966 and was assumed to originate from drinking water [16]. Two years later, it was discovered that human blood contains organic and inorganic FCs which were presumed to originate from environmental aspects of water, air, and soil [17]. The F and its compounds occur naturally in the environment through volcanic activities and weathering of bed-rock material. These activities release $\mathrm{F}$ into the soil, water, and air in different forms depending on the nature of the parent-rock material [18]. Anthropogenic activities such as industrialization and fertilizer applications also release FCs of different forms such as polymers and other precursors that react with the naturally occurring $\mathrm{F}$ in the environment to form novel FCs [19]. These novel FCs could be toxic to plants and animals including humans. Nonetheless, due to the limitations of analytical abilities, it was almost impossible to identify specific organic F [20]. With recent advances in analytical methods, specific forms of organic F particularly perfluorinated compounds (PFCs), perfluorooctanoate (PFOA), and perfluorooctanesulfonate (PFOS) have been identified in blood and environmental samples [21]. The number of novel FCs identified has augmented to more than 15 by 2005 which is startling [22]. Since then, researchers have been working on finding appropriate analytical methods for the identification and quantification of FCs, as it has been put out that PFOS and PFOA constitute only a small amount of FCs existing in the environment $[19,21,23-26]$.

\section{Targeted and Nontargeted Analysis of FCs}

Given a massive number of FCs in the environmental and biological matrices, its analysis presents a significant analytical challenge [27]. A limited number of FCs is quantified using liquid chromatography-tandem mass spectrometry (LC-MS-MS) [28], ionic or gas chromatography-mass spectrometry (GC-MS) [29], and high-resolution mass spectrometry (HR-MS) [30]. These techniques, however, cannot capture all FCs due to a lack of authentic standards.
The question of how many FCs are missed out during analysis therefore remains a puzzle.

Analytical methods developed for quantification of total F irrespective of the chemical form or molecular weight are used for rapid screening. These methods include combustion ion chromatography (CIC) [31], nondestructive methods (particle-induced gamma-ray emission spectroscopy (PIGES) [32], fluorine-19 nuclear magnetic resonance spectroscopy (19F NMR) [33]), and total oxidizing precursors (total oxidizable precursor (TOP) assay) [34]. Each of the above-mentioned methods captures a specific fraction of FCs in the samples. TOP assay technique guarantees unidentified organofluorines to be associated with PFAs, yet it is incapable of screening emerging FCs that cannot oxidize into accustomed PFAs. Therefore, this method necessitates the addition of authentic standards of PFAs to broaden its analysis capability [27].

On the other hand, the HR-MS data acquisition step is referred to as nontargeted because it is possible to decide on how to use the information provided (i.e., targeted, suspected, or nontargeted). Targeted involves matching with reference standards already available. Suspect screening does not necessitate the standard reference; instead, the precise mass and isotopic pattern from the molecular formula is used to determine the existing molecule. These two are referred to as targeted analysis because of the analysis of mass spectrometer (MS) data that comes after compound information. With nontargeted analysis, MS data come before compound information and therefore intend to disclose the composition of that particular sample. The nontargeted analysis that intends to establish the known and unknown molecular species of a particular element in a sample is referred to as selective nontargeted analysis [35].

Nontargeted analysis of nonmetals such as chlorine $(\mathrm{Cl})$, bromine (Br), and iodine (I) have so far not been exhausted. This is because of challenges such as low sensitivity in the plasma and interferences that lead to erroneous results [25]. Also, $\mathrm{Cl}$ and $\mathrm{F}$ have high ionization potentials and are therefore not effectively ionized in argon- (Ar-) based plasma; whereas $\mathrm{Br}$ is interfered with argides in ICP-MS. Chlorinated compounds have been determined in ESI-MS technique, although its quantification necessitates specific standards [36]. ICP-MS analysis of chlorinated compounds is limited by its high ionization energy and polyatomic interferences. Nevertheless, the use of tandem ICP-MS (ICPMS-MS) with hydrogen gas $\left(\mathrm{H}_{2}\right)$ as a reaction gas facilitates its analysis at limits of detection in parts-per-million [37]. On the other hand, analysis of $\mathrm{Br}$ has been reported to be successful where high-performance liquid chromatographytandem ICP-MS (HPLC-ICP-MS-MS) is utilized [38].

Initially, more than 4000 organofluorines compounds were identified. Those that were found not biodegradable were banned ( $\approx 15$ PFCs), and isotopically labeled standards were prepared for their nontargeted analysis using the HPLC-ESI-MS detection technique [19, 39, 40]. Later, researchers speculated the existence of novel PFCs precursors that could not be determined in ESI-MS. This is because authentic standards for the novel precursors were not available, and mathematical algorithm to determine 
molecular forms of $\mathrm{F}$ in an enormous amount of data generated during nontargeted analysis in ESI-MS was lacking [41]. The ESI-MS technique is cost-effective and easy to use but requires stable $\mathrm{pH}$ and ionic strength, and its sensitivity is also insufficient for low fluoride $\left(\mathrm{F}^{+}\right)$concentrations [42]. On the other hand, CIC is challenged with weak $\mathrm{F}^{+}$binding affinity to exchanging ions during the separation process. Weak binding affinity leads to early elution of $\mathrm{F}^{+}$species from the column producing erroneous results [4].

Spectroscopic methods such as atomic absorption spectrometry (AAS), laser-induced breakdown spectroscopy (LIBS), ICP-MS, and ICP-OES offer an indiscriminate analysis of FCs $[2,43]$. Due to the nature of F, the strongest atomic absorbance is at the vacuum-UV range beneath $100 \mathrm{~nm}$ [44]. This is beyond the working range of ICP-OES, LIBS, and AAS and therefore results in poor sensitivity. Determination of $\mathrm{F}$ in plasma-based techniques was therefore rated as almost impossible [43]. The use of the ICPMS technique for the determination of FCs has been faced with an insufficient amount of $\mathrm{F}^{+}$synthesized due to the high ionization energy potential of $\mathrm{F}$ together with spectral and nonspectral interferences. Analytical chemists have employed several techniques during utilization of ICP-MS to facilitate lower limits of detections, high $\mathrm{F}^{+}$concentrations in the plasma, and minimizing interferences while accomplishing selective nontargeted analysis [44] techniques that are discussed in this study.

\section{Inductively Coupled Plasma Mass Spectrometry (ICP-MS)}

ICP-MS is rated as a powerful technique in analytical chemistry (Figure 1). Its advantages over the rest of the ICP techniques are highlighted in Table 1. Determination of $\mathrm{F}$ by conventional ICP technique is impaired by its high ionization energy. However, an exception is made to helium(He-) (ionization energy: $24.6 \mathrm{eV}$ ) based plasma. Fluorine (F) is the most electronegative element with ionization energy exceeding that of $\mathrm{Ar}$ (the ionization energy of $\mathrm{F}$ and Ar is 17, 4228 and 15, $7596 \mathrm{eV}$, respectively). The high ionization energy of $\mathrm{F}$ compared to that of $\mathrm{Ar}$ is the cause of the low degree of ionization of $\mathrm{F}$ in Ar-based plasma. The combined effect of ionization energy, mass to charge ratio $(\mathrm{m} / \mathrm{z})(19$ for $\mathrm{F}$ and 36,38 , and 40 for Ar), and emission lines (nm) (95.187-97.774 for F and 80.286-106.666 for Ar) in low-vacuum UV makes F determination in ICP tools conventionally impracticable $[45,46]$. F analysis in ICP-MS is also hampered by spectral and nonspectral interferences which subsequently affect the quality of results as shown in Table 2 [51]. Spectral interferences occur when another species is detected at the same or close to the $\mathrm{m} / \mathrm{z}$ ratio of the analyte, whereas the nonspectral interference leads to suppression or augmentation of the signal [52]. The latter is also obtained during sample introduction, ion transport from ICP to Ar plasma interface, ion production in plasma, and ion optics to the spectrometer $[53,54]$.

\section{FCs Sample Preparation Methods for ICP- MS Analysis}

A sample for analysis by ICP-MS is normally diluted using nitric acid or hydrochloric acid to uphold its solubility [55]. Most water samples can easily be analyzed without any preparations. However, solid samples, such as plant material, soil, food, and sludge material, have to be digested in acid and then diluted to the appropriate total dissolved solids (less than 0.5\%) and acid concentration [55-57].

Determination of $\mathrm{F}$ using conventional quadrupole ICPMS is challenged by water-derived spectral interferences and tremendously low sensitivity [42]. Therefore, much attention during sample preparation and handling are needed to avoid analysis error. Furthermore, sample preparation before analysis protects the analytical instrument from corrosion, blockage, and contaminants thereby reducing interferences $[12,42,46]$. The disadvantage associated with sample preparation is a change in the composition of the sample. For example, if not handled appropriately during preparation, the sample of interest may change by becoming volatile and may eventually be lost [14].

The majority of FCs contains carbon-based compounds and salts which cause interferences [12]. High concentrations of carbon species in sample solution cause analyte signal augmentation in high and low ICP-MS resolutions due to charge transmission reactions. It is crucial to understand the probable interference before the determination of the procedure for process efficiency $[46,58]$. If the interference detection is at the desired limit, then the interferences can be matched with the sample and standard. If the detection limit is not at a critical limit, sample dilution or elimination is achieved to reduce or even remove the interferences completely [59].

Extraction is one of the methods used for the preparation of samples for $\mathrm{F}$ analysis. This method involves the use of alkaline solutions such as water-soluble tertiary amine solution (CFA-C), ammonia, tetramethylammonium hydroxide (TMAH), and sodium hydroxide $(\mathrm{NaOH})[37,46]$. Other $\mathrm{F}$ extraction methods reported involve the use of water [60], organic solvents [25], and acids [61].

Wet digestion is another sample preparation method used to prepare FCs. This method was used to determine F in blood serum, where ether was used as an extract followed by perchloric acid [62]. It is more efficient compared with other methods such as open ashing-fluoride electrode, oxygenbomb fluorine electrode, and oxygen-bomb gas chromatography in terms of $\mathrm{F}$ loss and contamination with extraneous F. The challenge of using this method is the fact that it releases volatile compounds such as HF which causes nonquantitative recoveries $[63,64]$. Therefore, the wet digestion method for FCs sample preparation requires novel ways to control the production of HF.

Decomposition methods of combustion and pyrohydrolysis [63, 65] use a concentrated solution [66]. Combustion methods that are used to prepare FCs samples include dry ashing $[11,67,68]$, combustion bomb [66, 69-71], Wick-bold apparatus [72], Schoniger flask [73], 


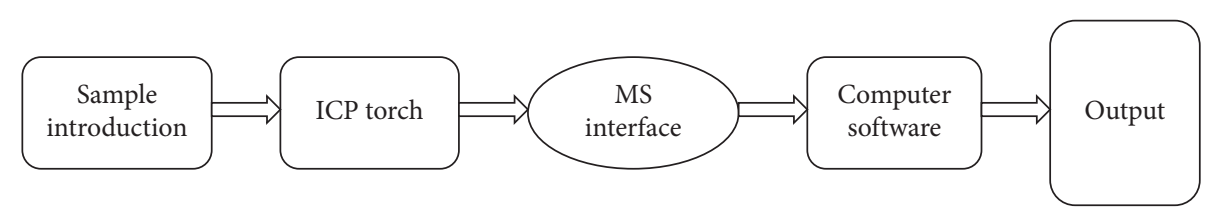

FigURE 1: ICP-MS system composition.

TABle 1: Comparison between OES, AAS, and ICP-MS [11].

\begin{tabular}{|c|c|c|c|}
\hline & AAS & ICP-OES & ICP-MS \\
\hline $\begin{array}{l}\text { Elemental } \\
\text { analysis }\end{array}$ & Identifies a single element at a time & $\begin{array}{l}\text { Capable of identifying the amount } \\
\text { of } \\
\text { multiple elements in a single sample }\end{array}$ & $\begin{array}{l}\text { Capable of identifying the amount of } \\
\text { multiple elements in a single sample }\end{array}$ \\
\hline Limit of detection & $\begin{array}{c}\text { Good limits of detection for many } \\
\text { elements }\end{array}$ & Better than AAS & $\begin{array}{c}\text { Provides the lowest limits of } \\
\text { detection }\end{array}$ \\
\hline Working range & 2 orders of magnitude & $\begin{array}{l}\text { Up to } 6 \text { orders of magnitude } \\
\qquad(1 \mu \mathrm{g} / \mathrm{L}-1 \mathrm{~g} / \mathrm{L})\end{array}$ & 9 orders of magnitude $(1 \mathrm{ng} / \mathrm{L}-1 \mathrm{~g} / \mathrm{L})$ \\
\hline Cost & Low & Medium & High \\
\hline Isotope analysis & No & No & $\begin{array}{l}\text { Capable of analyzing isotopes of } \\
\text { the same elements }\end{array}$ \\
\hline
\end{tabular}

and microwave-induced combustion [74-76]. These methods are effective; however, they can change sample composition. Methods without matrix decomposition such as dilution, filtration, and solubilization have also been used for the determination of FCs by ICP-MS [77]. These methods are fast and easy, reducing the time spent for sample preparation $[47,49,50,77]$, although they are prone to interferences and contamination of the plasma and nebulization system [25].

Currently, the commonly used FCs sample preparation methods are solid-phase extraction (SPE) and liquid-liquid extractions such as ion-pair extraction (IPE). Water samples are preferably extracted using SPE because it is fast, consumes less organic solvents, and integrates extraction and clean-up $[78,79]$. Initially, $\mathrm{C}_{18}$ SPE cartridges were used for the preparation of FCs samples; however, its use lately has narrowed due to the presence of trace polyfluorocarbon concentrations in its wrapping materials which tamper with F determination [3]. Weak anion exchange SPE cartridge (WAX) [56] is reported to produce the best extraction for most of FCs; whereas lipophile balance cartridge (HLB) [80] showed efficient extractions of few FCs. Semivolatile and volatile FCs are extracted using an emerging solid-phase microextraction method (SP-ME); however, this method requires derivatization because $\mathrm{F}$ tends to augment at the top of the sorbent [13, 81, 82]. IPE employs reagents such as $\mathrm{NaOH}$, methyl tertbutyl ether (MTBE), and tetrabutylammonium hydrogen sulfate (TBA) to extract FCs [83-85]. The FCs dissolve in alkali solution then reacts with TBA which can then be easily extracted by low polar solvent MTBE. IPE has an advantage that it can be used for a variety of samples as compared to SPE which is applied for liquid samples only [86].

Samples in a solid state such as soil, sludge, sediment, and plant are extracted using accelerated solvent extraction (ASE) [28] and ultrasonic extraction (UAE) [87]. The former method provides high efficiency under high temperature and pressure settings; however, it is uneconomical and therefore less preferred [88, 89]. For analysis of plant samples, preparation for $\mathrm{F}$ determination mixes several solvents due to the complex matrix composition. A single solvent does not provide efficient extraction. Yoo et al. (2011) used a solvent mixture of dichloromethane-methanol $(50: 50 \mathrm{v} / \mathrm{v})$ and methanol $(99: 1 \mathrm{v} / \mathrm{v})$ and ammonium hydroxide for plant samples extractions; the results were satisfactory [90] and were later supported with Blaine and coworkers who successfully used the same method [91].

\section{Sample Introduction into ICP-MS}

The nebulization process generates water mist during sample introduction which releases ${ }^{18} \mathrm{OH}^{+}$ions. These ${ }^{18} \mathrm{OH}^{+}$ions interfere with both detection and ionization of ${ }^{19} \mathrm{~F}^{+}$ion. A low-flow self-aspirating PFA nebulizer and a PFA spray chamber were investigated in hot plasma conditions to overcome the two challenges during sample introduction into the plasma for F determination in high resolution-ICPMS (HR-ICP-MS). The optimum nebulizer flow rate for a high ionization potential of $\mathrm{F}$ was achieved at $0.8 \mathrm{~L} / \mathrm{min}$. High gas-flow rate results in chill/cool plasma which affects F ionization. Hot plasma and low flow rates offer ample time for ionization of F. Moreover, fixed nebulizer gas flow rate at a higher radio frequency (RF) power leads to a hotter plasma and therefore favors F determination [47]. Another attempt to overcome the two challenges was reported by Yasuaki Okamoto (2001) who used electrothermal vaporization-ICPMS (ETV-ICP-MS) for sample introduction. In this technique, the sample insertion port is left open to allow liquid escape when the sample is heated at $200^{\circ} \mathrm{C}$ for $80 \mathrm{~s}$. When the sample has dried, the port is closed and the temperature is raised to $1100^{\circ} \mathrm{C}$ for vaporization. The cloud generated containing $\mathrm{F}^{+}$is instantly transported to the ICP by Ar gas. With this technique, the interfering ${ }^{18} \mathrm{OH}^{+}$ions were degraded, and the limit of detection (LOD) of $0.29 \mu \mathrm{g}$ was 


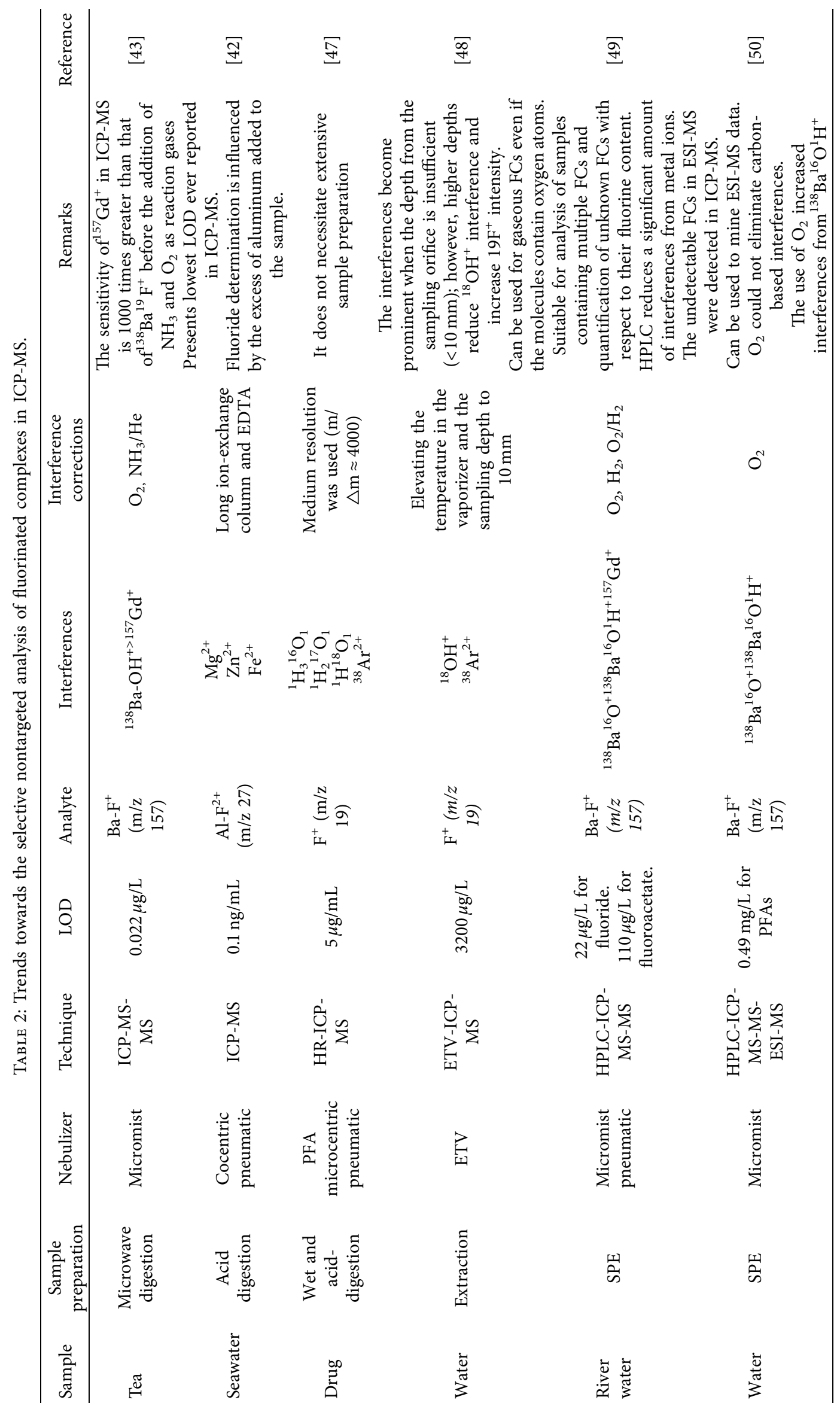


attained. The study also suggested increasing the RF power up to $1.4 \mathrm{~kW}$ to decrease integrated $\mathrm{F}^{+}$signals [48]. Lower $\mathrm{RF}$ power normally used in the nebulization system to eliminate molecular ions was not recommended for use as it leads to unstable plasma discharge and increased baseline as discussed in detail in the review [92].

\section{Mass Analyzers}

The main interferences encountered during quadrupoleICP-MS (ICP-QMS) application for analysis of FCs are isobaric, doubly charged, and polyatomic [63]. Isobaric interferences occur when signals of different ionic species with the same $\mathrm{m} / \mathrm{z}$ ratio overlap. To reduce isobaric interferences, isotopes with high natural abundance are preferred. This is because the abundance of the isotope determines the precision of its measurement [46]. The advantage is the fact that most elements have isotopes with unique mass numbers aiding their determination and quantification. Doubly charged interference results when the ions of an element exist with double rather than a common single positive charge $[12,25]$.

The formation of molecules in the plasma results in polyatomic interference [63]. This is when Ar reacts with elements such as hydrogen $(\mathrm{H})$, nitrogen $(\mathrm{N})$, and oxygen (O) amongst others originating from acids dissolving the samples. Amongst the reported $\mathrm{F}$ spectral interferences are ${ }^{38} \mathrm{Ar}^{2+},{ }^{1} \mathrm{H}^{18} \mathrm{O}^{+}$, and ${ }^{1} \mathrm{H}_{2}{ }^{16} \mathrm{O}^{1} \mathrm{H}^{+}$species [43, 77]. Plasmabased instruments have been modified to minimize these interferences. Amongst them are torch change [64], change of interface design, development of dynamic reaction cell technology [50,93], and hyphenation of ICP-MS with chromatographic methods [49].

The HR-ICP-MS was developed to minimize interferences where interference-free ${ }^{19} \mathrm{~F}^{+}$was feasible at a resolution of $\mathrm{m} / \triangle \mathrm{m} \approx 4000$ [43, 47]. Also, a high-resolution double-focusing sector field (HR-ICP-SF-MS) was used by Jakubowski et al. (1998) where high-resolution devices combined with high sensitivity and low background signals offered interference-free analysis [94]. Both of these techniques lessened interferences due to mass overlap, although factors such as operation cost, time, and complexity limit its use for $\mathrm{F}$ determination $[15,42,43]$.

In response to polyatomic interferences, efforts of producing metal-fluoride $\{\mathrm{M}-\mathrm{F}\}^{+}$ions to determine FCs has been made by separating produced ions from other polyatomic ions using ICP-MS-MS [43]. To separate the produced $\{\mathrm{M}-\mathrm{F}\}^{+}$ions from other polyatomic ions formed by the reaction and collision between ions present in the plasma, an understanding of their formation time is of importance. However, this depends on the energy required to dissociate their bond. Ions with small dissociation energy requirements disintegrate at high temperatures while those with high dissociation energy requirements remain stable at higher temperatures $[14,95]$. Therefore, if a molecular ion containing $\mathrm{F}^{+}$with first and second low ionization and high dissociation energy is formed in the plasma, the ICP-MS with a triple quadrupole device (ICP-QQQ) is employed to lessen interferences [4, 59].
Aluminum $\left(\mathrm{Al}^{3+}\right)$ was used to determine FCs in ICPQQQ by developing $\left\{\mathrm{Al}-\mathrm{F}_{3}\right\}^{+}$complex. Later, this was separated into $\mathrm{AlF}^{2+}$ and $\mathrm{Al}^{3+}$ in the ion-exchange column. Although the technique was fruitful, it encountered interferences from $\mathrm{Mg}^{2+}, \mathrm{Zn}^{2+}$, and $\mathrm{Fe}^{2+}$. The use of ethylenediaminetetraacetic acid (EDTA) to eliminate $\mathrm{Fe}^{2+}$ interference was successful with a LOD of $0.1 \mathrm{ng} / \mathrm{mL}$ [42]. Other studies $[43,95]$ attempted to mix barium $(\mathrm{Ba})$ solution with $\mathrm{F}$ solution to generate $\{\mathrm{Ba}-\mathrm{F}\}^{+}$ion in the plasma. This assumption was based on the fact that $\{\mathrm{Ba}-\mathrm{F}\}^{+}$has a low first and second ionization energy of 5.21 and $10 \mathrm{eV}$, respectively, and high dissociation energy of $6.39 \mathrm{eV} .019$ studied a nontargeted analysis of perfluorinated organic compounds (POCs) using ICP-QQQ through mixing Ba solution with an F-containing solution. The researchers monitored the signals of $\{\mathrm{Ba}-\mathrm{F}\}^{+}$at $\mathrm{m} / \mathrm{z}$ 157. The polyatomic interferences from ${ }^{138} \mathrm{Ba} \mathrm{OH}^{+}\left({ }^{138} \mathrm{Ba}^{18} \mathrm{O}^{1} \mathrm{H}^{+},{ }^{138} \mathrm{Ba}^{17} \mathrm{O}^{1} \mathrm{H}_{2}{ }^{+}\right.$, and $\left.{ }^{138} \mathrm{Ba}^{16} \mathrm{O}^{1} \mathrm{H}_{3}{ }^{+}\right)$ and ${ }^{157} \mathrm{Gd}^{+}$at the target $\mathrm{m} / \mathrm{z} 157$ were prominent; however, they were most pronounced from ${ }^{138} \mathrm{Ba}^{-} \mathrm{OH}^{+}$. To minimize

${ }^{138} \mathrm{Ba}^{-} \mathrm{OH}^{+}$interferences and attain a LOD of $0.05 \mathrm{mg} / \mathrm{L}$, a mass-shift approach was proposed [50].

A mass-shift approach enhances the capability of ICPQMS to filter stable ions from unstable ones. Oxygen $\left(\mathrm{O}_{2}\right)$ and ammonia $\left(\mathrm{NH}_{3}\right)$ are used as reaction gases in the ICP-QMS [43]. Its use revealed that $\mathrm{O}_{2}$ reacts with ${ }^{138} \mathrm{Ba}-\mathrm{OH}^{+}$and $\mathrm{NH}_{3}$ with $\{\mathrm{Ba}-\mathrm{F}\}^{+}$to form $\left.{ }^{138} \mathrm{Ba}^{19} \mathrm{~F}^{14} \mathrm{NH}_{3}\right)_{3}{ }^{+}$. The formed new molecules constitute high mass which enhances its separation from the interfering species and hence passes through the detector unaccompanied $[43,49]$. To further enhance selectivity, one quadrupole can be implanted upstream of the collision/reaction cell to allow ions of only one $\mathrm{m} / \mathrm{z}$ to enter the cell. This prevents the generation of new interferences. Guo et al. (2020) considered the economics of using ICPQQQ as it was far more expensive to be found in the majority of laboratories. These researchers used a single quadrupoleICP-QMS to determine total F concentration. When online, Ar dilution of the sample before reaching the ICP was used in a conventional ICP-QMS, $\{\mathrm{Ba}-\mathrm{F}\}^{+}$signal dropped 4.6 times, and background signal interferences from ${ }^{138} \mathrm{Ba}^{-} \mathrm{OH}^{+}$were lessened by approximately 40-fold [96].

Hyphenation of ICP-MS with HPLC for nontargeted analysis of unknown elemental compounds in matrices has been used for quite some time now. High thermal energy in the plasma enables ICP-MS to handle the nonvolatile mobile phase from HPLC [56]. Determination of FCs by HPLC-ICP-MS necessitates the production of fluoridepolyatomic ions such as $\{\mathrm{Ba}-\mathrm{F}\}^{+}[49]$ and $\{\mathrm{Al}-\mathrm{F}\}^{+}[42]$ and has the ability to remove emerging interferences through the application of the reaction/collision gas. The first study to analyze FCs using HPLC-ICP-MS was conducted by Jamari et al. (2017). In this study, the formation of fluoridepolyatomic ions of $\{\mathrm{Ba}-\mathrm{F}\}^{+}$was established for its determination in HPLC-ICP-MS/ESI-MS in the presence of $\mathrm{O}_{2}$ as a reaction gas and RF power of $1500 \mathrm{~W}$. Following the use of $\mathrm{O}_{2}$, interferences from other barium polyatomic were minimized and thus enabled $\mathrm{F}^{+}$determination. The LOD and limit of quantification (LOQ) observed were 0.022 and $0.085 \mathrm{mg} / \mathrm{L}$, respectively, for $\mathrm{F}$ and 0.11 and $0.18 \mathrm{mg} / \mathrm{L}$, respectively, for fluoroacetate [50]. 
Another study employed HPLC-ICP-MS/ESI-MS for identification and quantification of FCs together with their methyl esters as their degradation products. Two separation techniques were investigated: isocratic $70 \%$ methanol and acetonitrile/water. $\mathrm{F}^{+}$was determined as a polyatomic ion of $\{\mathrm{Ba}-\mathrm{F}\}^{+}$at $157 \mathrm{~m} / \mathrm{z}$. The organic mode of ICP-MS was used with parameters of the column $\mathrm{C}_{18}$ amide and optimized temperature $40^{\circ} \mathrm{C}$. The results from HPLC-ICP-MS chromatograms revealed additional peaks of methyl esters initially not detected in ESI-MS. The use of $\mathrm{O}_{2}$ as a reaction gas could not eliminate carbon interferences but rather augmented interferences from ${ }^{138} \mathrm{Ba}^{-} \mathrm{OH}^{+}$ions. Furthermore, the acetonitrile technique separated FCs well for both ICPMS and ESI-MS detection, whereas the isocratic technique produced broad peaks in ICP-MS but did not match peaks in ESI-MS. The LOD varied in range $0.49-0.84 \mathrm{mg} / \mathrm{L}$. However, they could be lowered 5 -fold by increasing the injection volume from $20 \mu \mathrm{g}$ to $100 \mu \mathrm{g}$ [49].

The benefit of using HPLC-ICP-MS for $\mathrm{F}^{+}$determination lies in its ability to reduce interference from metal ions such as praseodymium (Pr), gadolinium $(\mathrm{Gd})$, and additional $\mathrm{Ba}$ found in the sample by separation through HPLC. Quantification of $\mathrm{F}^{+}$using HPLC-ICP-MS yielded results similar to HR-ICP-MS and, therefore, suitable for matrices with multiple FCs [50]. Additionally, analysis of ultratrace levels of $\mathrm{F}^{+}$with the HPLC-ICP-MS detector requires the use of "s-lens" other than the commonly used "x-lens" [13]. Furthermore, the presence of Gd in the sample leads to interferences since Gd has the same $\mathrm{m} / \mathrm{z}$ as that of $\{\mathrm{Ba}-\mathrm{F}\}^{+}$; however, the addition of reaction gas such as $\mathrm{O}_{2}$ reacts with $\mathrm{Gd}$ to form $\mathrm{GdO}^{+}$with $\mathrm{m} / \mathrm{z} 173$ which creates a mass shift [50].

An effort to detect $\mathrm{F}^{-}$using ICP-QMS operating in the negative mode when the gas flow rate in the nebulizer was adjusted in the range of $0.6-0.7 \mathrm{~L} / \mathrm{min}$, provided the LOD $0.4 \mathrm{mg} / \mathrm{L}[7,97]$. Towards this mode, better $\mathrm{F}^{-}$detection was observed than in most positive modes, notwithstanding challenges such as lack of collision high background and reaction cells. Therefore, with today's technology of ICPQQQ, a negative mode of ICP-QMS could be used to lessen background polyatomic interfering ions [13].

\section{Calibration, Precision, and Accuracy}

The matrix effects in ICP-QMS are corrected by the addition of reaction cells which can be complicated and uneconomical. An alternative to this arrangement is the use of calibration strategies which can be executed easily in an economical manner. The calibration strategies reported for the analysis of FCs are external (EC) $[43,77]$ and internal calibration (IC) $[19,50]$.

Gou et al. (2017) used multiple-point EC during the determination of total $\mathrm{F}$ in food and tea samples using ICPMS-MS. A series of $F$ standard solutions ranging from 0.1 to $10 \mu \mathrm{g} / \mathrm{mL}$ was used to draw a calibration curve and then obtain a linear correlation coefficient $\left(R^{2}\right)=0.9999$. The accuracy of this method was dignified based on calculating the statistical difference between the witnessed values on the proposed method with those certified on purchased food-related standard reference materials (SRMs) [43]. Although EC is vastly preferred due to its simplicity, its use for complex matrix samples leads to inaccurate results. Bader (1980) reported EC to be unable to produce desired results when the calibration standard solution is different from the sample solution. Also, other factors such as $\mathrm{pH}$, ionic strength, physical-chemical properties, and temperature can produce inaccurate results even when total digestion is used for sample preparation [98]. The abovementioned challenges were observed during the analysis of other compounds but were not reported for FCs. Therefore, further studies to investigate the influence of the abovementioned challenges during the use of EC for the analysis of FCs are necessary.

The IC is useful because it enables the determination and quantification of new peaks in chromatograms. This advantage favors its application for nontargeted analysis arrangements. Jamari et al. (2019) used the IC method for nontargeted analysis of PFCs using HPLC-ICPMS/MS-ESIMS where two standards were spiked into the samples at varying concentrations. The calibration graphs generated revealed the ability of ICP-MS-MS to yield compound unspecific detection (nontargeted); however, this depends on a separation method used (the isocratic elution method is efficient) [50]. Similar results were also obtained from other studies including HR-ICP-MS [47, 49, 99].

While most studies did not give a reason as to the choice of an internal standard (IS) during IC, two main factors are of importance when selecting an IS. First, the analyte and IS should have comparable intensities and therefore signals, and second, both the analyte and IS should have the same physical-chemical properties so that they both undergo the same evolutions during analysis [100]. Some of the IS used for IC in the analysis of FCs include fluoride [47, 49], perfluorohexanoic acid (PFHxA), perfluorooctanoic acid (PFOA) [50], and PFOS and PFOA [99]. However, an insignificant amount of fluorine and shorter carbon chain IS for FCs leads to a smaller response as compared to long carbon chained due to differences in the transport efficiency within the plasma [50].

\section{Conclusion}

A supreme $\mathrm{F}$ analytical method should be able to perform a nontargeted determination and quantification with minimal or without sample prepreparation procedures efficiently. Most F analytical methods employed today necessitate extensive sample preparation and yet incapable of nontargeted analysis. The use of ICP-MS has demonstrated the ability to perform nontargeted analysis at low LOD successfully with the advancement in instrumentation and methodology. Although it still entails extensive sample preparation methods to reduce interferences during analysis, yet it is a promising technique. Hyphenation of ICP-MS to HPLC proved to be the most efficient method for the determination and quantification of FCs, particularly for interference minimization. Notwithstanding, little has been done on environmental samples. Also, the current advancements in the determination and quantification of FCs in the positive 
mode of ICP-MS could be explored in the negative mode of ICP-QMS for analysis of FCs.

\section{Conflicts of Interest}

The authors declare that there are no conflicts of interest.

\section{Acknowledgments}

This work was funded by the Partnership for Applied Skills in Sciences, Engineering and Technology-Regional Scholarship Innovation Fund (PASET-RSIF). The authors would like to acknowledge Dr. John Justo Ambuchi and Dr. Kafula Chisanga for their resourceful comments, suggestions, and editing contributions during the entire writing process.

\section{References}

[1] K. Inoue, F. Okada, R. Ito et al., "Perfluorooctane sulfonate (PFOS) and related perfluorinated compounds in human maternal and cord blood samples: assessment of PFOS exposure in a susceptible population during pregnancy," Environmental Health Perspectives, vol. 112, no. 11, pp. 1204-1207, 2004.

[2] L. W. Y. Yeung and S. A. Mabury, "Are humans exposed to increasing amounts of unidentified organofluorine?" Environmental Chemistry, vol. 13, no. 1, pp. 102-110, 2016.

[3] N. Yamashita, K. Kannan, S. Taniyasu et al., "Analysis of perfluorinated acids at parts-per-quadrillion levels in seawater using liquid chromatography-tandem mass spectrometry," Environmental Science \& Technology, vol. 38, no. 21, pp. 5522-5528, 2004.

[4] A. Dhillon, M. Nair, and D. Kumar, "Analytical methods for determination and sensing of fluoride in biotic and abiotic sources: a review," Analytical Methods, vol. 8, no. 27, pp. 5338-5352, 2016.

[5] J. Musijowski, B. Szostek, M. Koc, and M. Trojanowicz, "Determination of fluoride as fluorosilane derivative using reversed-phase HPLC with UV detection for determination of total organic fluorine," Journal of Separation Science, vol. 33, no. 17-18, pp. 2636-2644, 2010.

[6] M. C. McMaster, HPLC: A Practical User's Guide, John Wiley \& Sons, Hoboken, NJ, USA, 2007.

[7] G. H. Vickers, D. A. Wilson, and G. M. Hieftje, "Detection of negative ions by inductively coupled plasma mass spectrometry," Analytical Chemistry, vol. 60, no. 17, pp. 1808-1812, 1988.

[8] H. R. Bronstein and D. L. Manning, "Lanthanum trifluoride as a membrane in a reference electrode for use in certain molten fluorides," Journal of the Electrochemical Society, vol. 119, no. 2, p. 125, 1972.

[9] B. F. Abramović, F. F. Gaál, and S. D. Cvetković, “Titrimetric determination of fluoride in some pharmaceutical products used for fluoridation," Talanta, vol. 39, no. 5, pp. 511-515, 1992.

[10] V. L. Dressler, D. Pozebon, É zebonr Flores, J. N. G. Paniz, and É and G. Flores, "Potentiometric determination of fluoride in geological and biological samples following pyrohydrolytic decomposition," Analytica Chimica Acta, vol. 466, no. 1, pp. 117-123, 2002.

[11] S. S. Nielsen, Food Analysis, Springer, Berlin, Germany, 2010.

[12] S. S. Nielsen, "Introduction to food analysis," in Food Analysis, pp. 3-16, Springer, Berlin, Germany, 2017.
[13] A. Koch, R. Aro, T. Wang, and L. W. Y. Yeung, "Towards a comprehensive analytical workflow for the chemical characterisation of organofluorine in consumer products and environmental samples," TrAC Trends in Analytical Chemistry, vol. 123, Article ID 115423, 2020.

[14] L. Balcaen, E. Bolea-Fernandez, M. Resano, and F. Vanhaecke, "Inductively coupled plasma-tandem mass spectrometry (ICP-MS/MS): a powerful and universal tool for the interference-free determination of (ultra) trace elements-a tutorial review," Analytica Chimica Acta, vol. 894, pp. 7-19, 2015.

[15] J. Carr, A. Dill, K. Kwok, J. Carnahan, and G. Webster, "LCICP-MS for nonmetal selective detection of pharmaceuticals," Current Pharmaceutical Analysis, vol. 4, no. 4, pp. 206-214, 2008.

[16] D. R. Taves, "Normal human serum fluoride concentrations," Nature, vol. 211, no. 5045, pp. 192-193, 1966.

[17] D. R. Taves, "Evidence that there are two forms of fluoride in human serum," Nature, vol. 217, no. 5133, pp. 1050-1051, 1968.

[18] X. Zhang, S. Gong, Z. Shen et al., "Characterization of soil dust aerosol in China and its transport and distribution during 2001 ACE-Asia: 1. Network observations," Journal of Geophysical Research: Atmospheres, vol. 108, 2003.

[19] Y. Miyake, N. Yamashita, M. K. So et al., "Trace analysis of total fluorine in human blood using combustion ion chromatography for fluorine: a mass balance approach for the determination of known and unknown organofluorine compounds," Journal of Chromatography A, vol. 1154, no. 12, pp. 214-221, 2007.

[20] R. Ranjan and A. Ranjan, Fluoride Toxicity in Animals, Springer, Berlin, Germany, 2015.

[21] H. Fiedler, "National PCDD/PCDF release inventories under the Stockholm convention on persistent organic pollutants," Chemosphere, vol. 67, no. 9, pp. S96-S108, 2007.

[22] S. Taniyasu, K. Kannan, M. K. So et al., "Analysis of fluorotelomer alcohols, fluorotelomer acids, and short- and longchain perfluorinated acids in water and biota," Journal of Chromatography A, vol. 1093, no. 1-2, pp. 89-97, 2005.

[23] L. W. Y. Yeung, Y. Miyake, S. Taniyasu et al., "Perfluorinated compounds and total and extractable organic fluorine in human blood samples from China," Environmental Science \& Technology, vol. 42, no. 21, pp. 8140-8145, 2008.

[24] E. F. Houtz and D. L. Sedlak, "Oxidative conversion as a means of detecting precursors to perfluoroalkyl acids in urban runoff," Environmental Science \& Technology, vol. 46, no. 17, pp. 9342-9349, 2012.

[25] P. A. Mello, J. S. Barin, F. A. Duarte et al., "Analytical methods for the determination of halogens in bioanalytical sciences: a review," Analytical and Bioanalytical Chemistry, vol. 405, no. 24, pp. 7615-7642, 2013.

[26] M. Ateia, A. Maroli, N. Tharayil, and T. Karanfil, "The overlooked short- and ultrashort-chain poly- and perfluorinated substances: a review," Chemosphere, vol. 220, pp. 866-882, 2019.

[27] L. Schultes, G. F. Peaslee, J. D. Brockman et al., "Total fluorine measurements in food packaging: how do current methods perform?" Environmental Science \& Technology Letters, vol. 6, no. 2, pp. 73-78, 2019.

[28] H. F. Schröder, "Determination of fluorinated surfactants and their metabolites in sewage sludge samples by liquid chromatography with mass spectrometry and tandem mass spectrometry after pressurised liquid extraction and separation on fluorine-modified reversed-phase sorbents," 
Journal of Chromatography A, vol. 1020, no. 1, pp. 131-151, 2003.

[29] W. C. Percival, "Quantitative determination of fluorinated hydrocarbons by gas chromatography," Analytical Chemistry, vol. 29, no. 1, pp. 20-24, 1957.

[30] C. Blondel, P. Cacciani, C. Delsart, and R. Trainham, "Highresolution determination of the electron affinity of fluorine and bromine using crossed ion and laser beams," Physical Review A, vol. 40, no. 7, p. 3698, 1989.

[31] L. Schultes, "Fluorine mass balance in wildlife and consumer products: how much organofluorine are we missing?" Department of Environmental Science and Analytical Chemistry, Stockholm, Sweden, 2019.

[32] E. E. Ritter, M. E. Dickinson, J. P. Harron et al., "PIGE as a screening tool for Per- and polyfluorinated substances in papers and textiles," Nuclear Instruments and Methods in Physics Research Section B: Beam Interactions with Materials and Atoms, vol. 407, pp. 47-54, 2017.

[33] D. A. Ellis, J. W. Martin, D. C. G. Muir, and S. A. Mabury, "Development of an 19F NMR method for the analysis of fluorinated acids in environmental water samples," Analytical Chemistry, vol. 72, no. 4, pp. 726-731, 2000.

[34] C. Zhang, Z. R. Hopkins, J. McCord, M. J. Strynar, and D. R. U. Knappe, "Fate of per- and polyfluoroalkyl ether acids in the total oxidizable precursor assay and implications for the analysis of impacted water," Environmental Science \& Technology Letters, vol. 6, no. 11, pp. 662-668, 2019.

[35] M. Kunzelmann, M. Winter, M. Åberg, K.-E. Hellenäs, and J. Rosén, "Non-targeted analysis of unexpected food contaminants using LC-HRMS," Analytical and Bioanalytical Chemistry, vol. 410, no. 22, pp. 5593-5602, 2018.

[36] B. Rao, P. B. Hatzinger, J. K. Böhlke et al., "Natural chlorate in the environment: application of a new IC-ESI/MS/MS method with a Cl18O3-internal standard," Environmental Science \& Technology, vol. 44, no. 22, pp. 8429-8434, 2010.

[37] M. Bettinelli, S. Spezia, C. Minoia, and A. Ronchi, "Determination of chlorine, fluorine, bromine, and iodine in coals with ICP-MS and IC," Atomic Spectroscopy, vol. 23, pp. 105-110, 2002.

[38] F. Cuyckens, L. I. L. Balcaen, K. De Wolf et al., "Use of the bromine isotope ratio in HPLC-ICP-MS and HPLC-ESI-MS analysis of a new drug in development," Analytical and Bioanalytical Chemistry, vol. 390, no. 7, pp. 1717-1729, 2008.

[39] V. L. Dressler, D. Pozebon, É zebonr Flores, J. N. G. Paniz, and É and G. Flores, "Determination of fluoride in coal using pyrohydrolysis for analyte separation," Journal of the Brazilian Chemical Society, vol. 14, no. 2, pp. 334-338, 2003.

[40] B. Peng, D. Wu, J. Lai, H. Xiao, and P. Li, "Simultaneous determination of halogens $(\mathrm{F}, \mathrm{Cl}, \mathrm{Br}$, and $\mathrm{I})$ in coal using pyrohydrolysis combined with ion chromatography," Fuel, vol. 94, pp. 629-631, 2012.

[41] T. Kind and O. Fiehn, "Advances in structure elucidation of small molecules using mass spectrometry," Bioanalytical Reviews, vol. 2, no. 1-4, pp. 23-60, 2010.

[42] M. M. Bayón, A. R. Garcia, J. Ignacio García Alonso, and A. Sanz-Medel, "Indirect determination of trace amounts of fluoride in natural waters by ion chromatography: a comparison of on-line post-column fluorimetry and ICP-MS detectors," The Analyst, vol. 124, no. 1, pp. 27-31, 1999.

[43] W. Guo, L. Jin, S. Hu, and Q. Guo, "Method development for the determination of total fluorine in foods by tandem inductively coupled plasma mass spectrometry with a massshift strategy," Journal of Agricultural and Food Chemistry, vol. 65, no. 16, pp. 3406-3412, 2017.
[44] J. Fresen, F. Cox, and M. Witter, "The determination of fluoride in biological materials by means of gas chromatography," Pharmaceutisch Weekblad, vol. 103, no. 33, pp. 909-914, 1968.

[45] H. Wang, N. Lin, K. Kahen, H. Badiei, and K. Jorabchi, "Plasma-assisted reaction chemical ionization for elemental mass spectrometry of organohalogens," Journal of The American Society for Mass Spectrometry, vol. 25, no. 4, pp. 692-695, 2014.

[46] M. F. Mesko, V. C. Costa, R. S. Picoloto, C. A. Bizzi, and P. A. Mello, "Halogen determination in food and biological materials using plasma-based techniques: challenges and trends of sample preparation," Journal of Analytical Atomic Spectrometry, vol. 31, no. 6, pp. 1243-1261, 2016.

[47] X. Bu, T. Wang, and G. Hall, "Determination of halogens in organic compounds by high resolution inductively coupled plasma mass spectrometry (HR-ICP-MS)," Journal of Analytical Atomic Spectrometry, vol. 18, no. 12, pp. 1443-1451, 2003.

[48] Y. Okamoto, "Determination of fluorine in aqueous samples by electrothermal vaporisation inductively coupled plasma mass spectrometry (ETV-ICP-MS)," Journal of Analytical Atomic Spectrometry, vol. 16, no. 6, pp. 539-541, 2001.

[49] N. L. A. Jamari, J. F. Dohmann, A. Raab, E. M. Krupp, and J. Feldmann, "Novel non-target analysis of fluorine compounds using ICPMS/MS and HPLC-ICPMS/MS," Journal of Analytical Atomic Spectrometry, vol. 32, no. 5, pp. 942950, 2017.

[50] N. L. A. Jamari, J. F. Dohmann, A. Raab, E. M. Krupp, and J. Feldmann, "Novel non-targeted analysis of perfluorinated compounds using fluorine-specific detection regardless of their ionisability (HPLC-ICPMS/MS-ESI-MS)," Analytica Chimica Acta, vol. 1053, pp. 22-31, 2019.

[51] S. F. Boulyga and K. G. Heumann, "Direct determination of halogens in powdered geological and environmental samples using isotope dilution laser ablation ICP-MS," International Journal of Mass Spectrometry, vol. 242, no. 2-3, pp. 291-296, 2005.

[52] V. V. Salov, J. Yoshinaga, Y. Shibata, and M. Morita, "Determination of inorganic halogen species by liquid chromatography with inductively coupled argon plasma mass spectrometry," Analytical Chemistry, vol. 64, no. 20, pp. 2425-2428, 1992.

[53] C. Agatemor and D. Beauchemin, "Matrix effects in inductively coupled plasma mass spectrometry: a review," Analytica Chimica Acta, vol. 706, no. 1, pp. 66-83, 2011.

[54] C. Agatemor and D. Beauchemin, "Towards the reduction of matrix effects in inductively coupled plasma mass spectrometry without compromising detection limits: the use of argon-nitrogen mixed-gas plasma," Spectrochimica Acta Part B: Atomic Spectroscopy, vol. 66, no. 1, pp. 1-11, 2011.

[55] Y. Pomeranz, Food Analysis: Theory and Practice, Springer Science \& Business Media, Berlin, Germany, 2013.

[56] J. Feldmann, A. Raab, and E. M. Krupp, "Importance of ICPMS for speciation analysis is changing: future trends for targeted and non-targeted element speciation analysis," Analytical and Bioanalytical Chemistry, vol. 410, no. 3, pp. 661-667, 2018.

[57] S. Wilschefski and M. Baxter, "Inductively coupled plasma mass spectrometry: introduction to analytical aspects," Clinical Biochemist Reviews, vol. 40, no. 3, p. 115, 2019.

[58] S. Teng-Fei, L. Xiang, C. Lei et al., "Research progresses of determination of perfluorinated compounds in environmental 
water and solid samples," Chinese Journal of Analytical Chemistry, vol. 45, no. 4, pp. 601-610, 2017.

[59] H. Yahyavi, M. Kaykhaii, and M. Mirmoghaddam, "Recent developments in methods of analysis for fluoride determination," Critical Reviews in Analytical Chemistry, vol. 46, no. 2, pp. 106-121, 2016.

[60] A. M. Dolgonosov, R. K. Khamizov, and N. K. Kolotilina, "Nano ion exchangers as modifiers of chromatographic phases and sources of analytical signal," Journal of Analytical Chemistry, vol. 74, no. 4, pp. 382-392, 2019.

[61] G. Singh, B. Kumari, G. Sinam, N. Kriti, N. Kumar, and S. Mallick, "Fluoride distribution and contamination in the water, soil and plants continuum and its remedial technologies, an Indian perspective-a review," Environmental Pollution, vol. 239, pp. 95-108, 2018.

[62] P. Venkateswarlu, M. A. Lacroix, and G. W. Kirsch, "Determination of organic (covalent) fluorine in blood serum by furnace molecular absorption spectrometry," Microchemical Journal, vol. 48, no. 1, pp. 78-85, 1993.

[63] E. M. Flores, P. A. Mello, S. R. Krzyzaniak, V. H. Cauduro, and R. S. Picoloto, "Challenges and trends for halogen determination by inductively coupled plasma mass spectrometry: a review," Rapid Communications in Mass Spectrometry, vol. 34, p. e8727, 2020.

[64] C. T. Gross, S. M. McIntyre, and R. S. Houk, "Reduction of matrix effects in inductively coupled plasma mass spectrometry by flow injection with an unshielded torch," Analytical Chemistry, vol. 81, no. 12, pp. 4898-4905, 2009.

[65] J. C. Warf, W. D. Cline, and R. D. Tevebaugh, "Pyrohydrolysis in determination of fluoride and other halides," Analytical Chemistry, vol. 26, no. 2, pp. 342-346, 1954.

[66] D. Pavlović, M. Ponikvar-Svet, and J. F. Liebman, "Paradoxes and paradigms: observations on pyrohydrolysis, oxygen bomb combustion, and alkaline carbonate fusion, most frequently used decomposition methods for subsequent determination of fluorine and accompanying thermochemistry," Structural Chemistry, vol. 29, pp. 1247-1254, 2018.

[67] G. Grindlay, J. Mora, M. de Loos-Vollebregt, and F. Vanhaecke, "A systematic study on the influence of carbon on the behavior of hard-to-ionize elements in inductively coupled plasma-mass spectrometry," Spectrochimica Acta Part B: Atomic Spectroscopy, vol. 86, pp. 42-49, 2013.

[68] R. Bok, A Handbook of Decomposition Methods in Analytical Chemistry, International Atomic Energy Agency, Vienna, Austria, 1984.

[69] J. Thomas and H. J. Gluskoter, "Determination of fluoride in coal with the fluoride ion-selective electrode," Analytical Chemistry, vol. 46, no. 9, pp. 1321-1323, 1974.

[70] Z. Sulcek and P. Povondra, Methods of Decomposition in Inorganic Analysis, Springer, Cham, Switzerland, 1989.

[71] D. A. Levaggi, W. Oyung, and M. Feldstein, "Microdetermination of fluoride in vegetation by oxygen bomb combustion and fluoride ion electrode analysis," Journal of the Air Pollution Control Association, vol. 21, no. 5, pp. 277-279, 1971.

[72] P. B. Sweetser, "Decomposition of organic fluorine compounds by Wickbold oxyhydrogen flame combustion method," Analytical Chemistry, vol. 28, no. 11, pp. 1766-1768, 1956.

[73] B. Z. Senkowski, E. G. Wollish, and E. G. E. Shafer, "Rapid determination of organically bound fluorine," Analytical Chemistry, vol. 31, no. 9, pp. 1574-1576, 1959.
[74] A. L. G. Mendes, M. S. Nascimento, R. S. Picoloto, E. M. M. Flores, and P. A. Mello, "A sample preparation method for fluoride detection by potentiometry with ionselective electrode in medicinal plants," Journal of Fluorine Chemistry, vol. 231, Article ID 109459, 2020.

[75] R. S. Picoloto, M. S. P. Enders, M. Doneda et al., "An in situ pre-concentration method for fluorine determination based on successive digestions by microwave-induced combustion," Talanta, vol. 194, pp. 314-319, 2019.

[76] A. L. H. Müller, C. C. Müller, F. G. Antes et al., "Determination of bromide, chloride, and fluoride in cigarette tobacco by ion chromatography after microwave-induced combustion," Analytical Letters, vol. 45, no. 9, pp. 1004-1015, 2012.

[77] Y. Zhu, K. Nakano, and Y. Shikamori, "Analysis of fluorine in drinking water by ICP-qms/QMS with an octupole reaction cell," Analytical Sciences, vol. 33, no. 11, pp. 1279-1284, 2017.

[78] C. González-Barreiro, E. Martínez-Carballo, A. Sitka, S. Scharf, and O. Gans, "Method optimization for determination of selected perfluorinated alkylated substances in water samples," Analytical and Bioanalytical Chemistry, vol. 386, no. 7-8, pp. 2123-2132, 2006.

[79] J. S. Boone, B. Guan, C. Vigo, T. Boone, C. Byrne, and J. Ferrario, "A method for the analysis of perfluorinated compounds in environmental and drinking waters and the determination of their lowest concentration minimal reporting levels," Journal of Chromatography A, vol. 1345, pp. 68-77, 2014.

[80] C.-H. Lee, D.-H. Kim, K.-T. Sim, S.-Y. Park, I.-Y. Chung, and K.-S. Seok, "Separation characteristics of perfluorinated compounds in different cartridge types using LC-MS/MS," in Proceedings of the Korean Society for Analytical Science Conference, p. 239, Jeju Island, Korea, 2017.

[81] X. Li, P. Gan, R. Peng, C. Huang, and H. Yu, "Determination of 23 organophosphorous pesticides in surface water using SPME followed by GC-MS," Journal of Chromatographic Science, vol. 48, no. 3, pp. 183-187, 2010.

[82] W. Li-Na and Y. Jin-Liang, "Rapid determination of fluoride content in water by a comprehensive ion testing instrument," Chinese Journal of Health Laboratory Technology, vol. 11, 2008.

[83] S. Felizeter, M. S. McLachlan, and P. De Voogt, "Uptake of perfluorinated alkyl acids by hydroponically grown lettuce (Lactuca sativa)," Environmental Science \& Technology, vol. 46, no. 21, pp. 11735-11743, 2012.

[84] R. Vestergren, S. Ullah, I. T. Cousins, and U. Berger, “A matrix effect-free method for reliable quantification of perfluoroalkyl carboxylic acids and perfluoroalkane sulfonic acids at low parts per trillion levels in dietary samples," Journal of Chromatography A, vol. 1237, pp. 64-71, 2012.

[85] S. Ullah, T. Alsberg, R. Vestergren, and U. Berger, "Determination of perfluoroalkyl carboxylic, sulfonic, and phosphonic acids in food," Analytical and Bioanalytical Chemistry, vol. 404, no. 8, pp. 2193-2201, 2012.

[86] M. Honda, M. Robinson, and K. Kannan, “A rapid method for the analysis of perfluorinated alkyl substances in serum by hybrid solid-phase extraction," Environmental Chemistry, vol. 15, no. 2, pp. 92-99, 2018.

[87] V. C. Costa, R. M. Pereira, J. E. Mello, J. R. Brum, R. S. Picoloto, and M. F. Mesko, "Indirect determination of chlorine and fluorine in eye shadow by ion chromatography after an eco-friendly sample preparation method based on 
combustion reaction," Microchemical Journal, vol. 150, p. 104125, 2019.

[88] X. Xu, X.-H. Ying, and B.-W. Duan, "Determination of trace fluoride in plant material by ion chromatography," Journal of Instrumental Analysis, vol. 27, p. 57, 2008.

[89] A. Q. O. AQO, "Absolute area coverage (AAC\%) 48, 150, 156 accelerated solvent extraction (ASE) 209 acenaphthylene 99 acetogenic 191," in Proceedings of the 2013 International Network of Environmental Forensics Conference, p. 241, State College, PA, USA, 2014.

[90] H. Yoo, J. W. Washington, T. M. Jenkins, and J. J. Ellington, "Quantitative determination of perfluorochemicals and fluorotelomer alcohols in plants from biosolid-amended fields using LC/MS/MS and GC/MS," Environmental Science \& Technology, vol. 45, no. 19, pp. 7985-7990, 2011.

[91] A. C. Blaine, C. D. Rich, L. S. Hundal et al., "Uptake of perfluoroalkyl acids into edible crops via land applied biosolids: field and greenhouse studies," Environmental Science \& Technology, vol. 47, no. 24, pp. 14062-14069, 2013.

[92] M. Aramendía, M. Resano, and F. Vanhaecke, "Electrothermal vaporization-inductively coupled plasma-mass spectrometry: a versatile tool for tackling challenging samples," Analytica Chimica Acta, vol. 648, no. 1, pp. 23-44, 2009.

[93] S. D. Tanner, V. I. Baranov, and D. R. Bandura, "Reaction cells and collision cells for ICP-MS: a tutorial review," Spectrochimica Acta Part B: Atomic Spectroscopy, vol. 57, no. 9, pp. 1361-1452, 2002.

[94] N. Jakubowski, L. Moens, and F. Vanhaecke, "Sector field mass spectrometers in ICP-MS," Spectrochimica Acta Part B: Atomic Spectroscopy, vol. 53, no. 13, pp. 1739-1763, 1998.

[95] N. Yamada, Feasibility Study of Fluorine Detection by ICPQQQ, p. 33, Agilent Technologies, Santa Clara, CA, USA, 2013.

[96] W. Guo, X. Lin, L. Jin, and S. Hu, "Single quadrupole inductively coupled plasma-mass spectrometry for the measurement of fluorine in tea infusions and its health risk assessment," Journal of Food Composition and Analysis, vol. 86, Article ID 103378, 2020.

[97] M. Chtaib and J.-P. Schmit, "Negative-ion mode in inductively coupled plasma mass spectrometry," Journal of Analytical Atomic Spectrometry, vol. 3, no. 2, pp. 315-318, 1988.

[98] M. Bader, "A systematic approach to standard addition methods in instrumental analysis," Journal of Chemical Education, vol. 57, no. 10, p. 703, 1980.

[99] S. Taniyasu, K. Kannan, Q. Wu et al., "Inter-laboratory trials for analysis of perfluorooctanesulfonate and perfluorooctanoate in water samples: performance and recommendations," Analytica Chimica Acta, vol. 770, pp. 111-120, 2013.

[100] W. B. Barnett, V. A. Fassel, and R. N. Kniseley, "An experimental study of internal standardization in analytical emission spectroscopy," Spectrochimica Acta Part B: Atomic Spectroscopy, vol. 25, no. 3, pp. 139-161, 1970. 